\title{
Enhancing the separation of nano-sized particles in low-salt suspensions by electrically assisted cross-flow filtration
}

\author{
Menghau Sung ${ }^{a}$, C.P. Huang ${ }^{b, *}$, Yu-Hsiang Weng ${ }^{c}$, \\ Yao-Tung Lin ${ }^{\mathrm{d}}$, Kung-Cheh $\mathrm{Li}^{\mathrm{c}}$ \\ a Department of Environmental Engineering and Science, Chia-Nan University of Pharmacy and Science, Tainan 717, Taiwan, ROC \\ ${ }^{\mathrm{b}}$ Department of Civil and Environmental Engineering, University of Delaware, Newark, DE 19716, USA \\ ${ }^{\mathrm{c}}$ Graduate Institute of Environmental Engineering, National Taiwan University, Taipei 106, Taiwan, ROC \\ ${ }^{\mathrm{d}}$ Department of Soil Environment, National Chunghsing University, Taichung, Taiwan, ROC
}

Received 17 November 2005; received in revised form 22 August 2006; accepted 1 September 2006

\begin{abstract}
A cross-flow filtration module with a large pore-size membrane and low operation pressure was built, as a first attempt, to test its performance on the separation of synthetic nano-sized alumina and silica particles in the presence of an electric field. For practicality sake, turbidity measurements were used primarily to evaluate the particle removal efficiency and to determine critical currents. The observed critical currents agreed well with theoretically calculated. The critical currents observed were found to be strongly dependent on the conductivity; there was a linear relationship between the critical current and conductivity. Further theoretical analysis of the electrical filtration module reveals that particles of different size or surface charge (e.g., zeta potential) can be separated within a particular size range by controlling the ionic strength or the conductivity of the solution.
\end{abstract}

(C) 2006 Published by Elsevier B.V.

Keywords: Electrofiltration; Nano-sized particles; Alumina; Silica; Particle separation; Critical current

\section{Introduction}

Naturally occurring particles are ubiquitous in subsurface and surface water systems. Depending on the chemical composition, particles can be contaminants themselves or become indirect contaminants by adsorbing hazardous organic compounds and heavy metals [1-3]. As a result, aquatic particles can play an important role in contaminant transport. Thus, efforts to characterize them in terms of surface charge, particle size, and chemical composition [4-6] are crucial. Up to now, methodologies to collect particulate samples representative of field conditions remain a difficult and challenging task. Current practice to differentiate solid into "soluble" and "insoluble" fractions is done by filtering water samples through 0.45 - $\mu \mathrm{m}$ filters. This does not adequately reflect the actual distribution of chemical species in water, e.g., metals adsorbed on surface of nano- to submicron particles [7]. The "dissolved" portion consists mainly

\footnotetext{
* Corresponding author. Tel.: +1 302831 8428; fax: +1 3028313640.

E-mail address: huang@ce.udel.edu (C.P. Huang).
}

of sub-micron colloids, which have high adsorption capacity for natural macromolecules, organic contaminants [8], metal ions [9] and radionuclides [10]. As an alternative, ultrafiltration has been used [11] to sample colloids of various sizes followed by sequential extraction of chemical species of interest using various procedures [12]. However, membrane fouling is still a problem due to the wide size range, chemical heterogeneity, the physiochemical affinity of particles to the membrane, and various side effects such as surface coagulation, sample perturbation, adsorption, and biological cell rupture. In addition, it is known that colloidal particles in natural waters are in principle unstable. Therefore, to achieve results representative of natural water samples, it is necessary to characterize colloids as quickly as possible [11]. Otherwise, the fate and transport of contaminants associated with particulate particles cannot be determined. Consequently, an easy and effective separation method to characterize environmental particles is urgently needed.

It has been reported that applying an external electrical field across the filter membrane (e.g., electrofiltration) can reduce membrane fouling and thereby enhance the flux during filtration. 
For instance, Weigert et al. [13] have shown that a 10-fold flux increase can be attained during microfiltration of slurries containing $\mathrm{SiO}_{2}$ at an average size of $3000 \mathrm{~nm}$. Huotari et al. [14] also have reported a five-fold increase in permeate flux during electrofiltration of oil emulsions. In order to minimize energy consumption, several researchers have proposed to apply the electric field in a pulsed rather than steady fashion $[15,16]$. The above electrofiltration studies essentially focused on increasing the permeate flux by manipulating the electric voltage. It was observed that as the voltage increased, the cake layers deposited on the membrane surface became thinner. Eventually when the critical voltage - the voltage at which the particles are kept stationary as to yield a steady flux — is reached, there is no particle deposition on the membrane surface. Applying at the critical voltage has greatly mitigated membrane fouling problems and prolonged the frequency of its cleaning, e.g., backwash.

In electrofiltration systems, the membrane pore size is made smaller than the particulates in order to achieve desired separation. When a higher permeate flux is needed, a higher pressure has to be applied, and a correspondingly higher critical voltage would be needed since the critical voltage is highly dependent on permeate flux. In principle, if a correct critical voltage were applied during filtration, a membrane would not be needed, since the electric force alone can achieve separation. Practically, this design is not feasible because it would reduce permeate flux significantly. However, it can serve as a viable alternative for the characterization of environmental particles since a low permeates flux is acceptable in this case. Such an electrophoretic separation can avoid the aforesaid problems of membrane-assisted sampling, warrant a simple procedure, and make real-time monitoring possible.

In this study, an electrophoretic separation device that utilized only electrostatic force to separate colloids was constructed for the sampling of environmental particulates. Unlike the traditional electrofiltration unit, it had large membrane pores and was operated at a low pressure. Prior to field applications, its performance on synthetic particles were evaluated. Specific objectives of this study were: (1) to evaluate the effects of pertinent parameters such as $\mathrm{pH}$, zeta potential, and conductivity on the separation of nano-sized particles exemplified by alumina and silica colloids, (2) to determine the critical currents under various conditions, and (3) to verify the critical currents as predicted theoretically.

\section{Materials and methods}

Fig. 1 shows the design of the electro-filtration system. To maximize the retention time of particles within a specific surface area, a multi-channel system was built using Plexiglass. The concentrate cell, which consists of two perforated stainless-steel electrodes, was placed above the permeate cell. Two cells were screwed together with the membrane and the cathode electrode in between. The polarity of the anode and cathode was switched according to the surface charge characteristics of particles in the suspension. In most cases, the anode was the upper piece and the cathode was the lower component (see the front side view in Fig. 1), since most of the aquatic particles were negatively charged. Electrodes were connected to a power supply, which controlled the magnitude of the voltage applied or field strength. The Goretex ${ }^{\mathrm{TM}}$ (Maryland, USA) membrane with a $3-\mu \mathrm{m}$ pore size was placed on top of the cathode, which also served as a support for the membrane. The volume of the concentrate and the permeate cells were both $930 \mathrm{~mL}$. Due to intrinsic limitations of the cell and electrode materials used, it was not appropriate to operate the system at a voltage that is higher than $200 \mathrm{~V}$ due to corrosion concern.

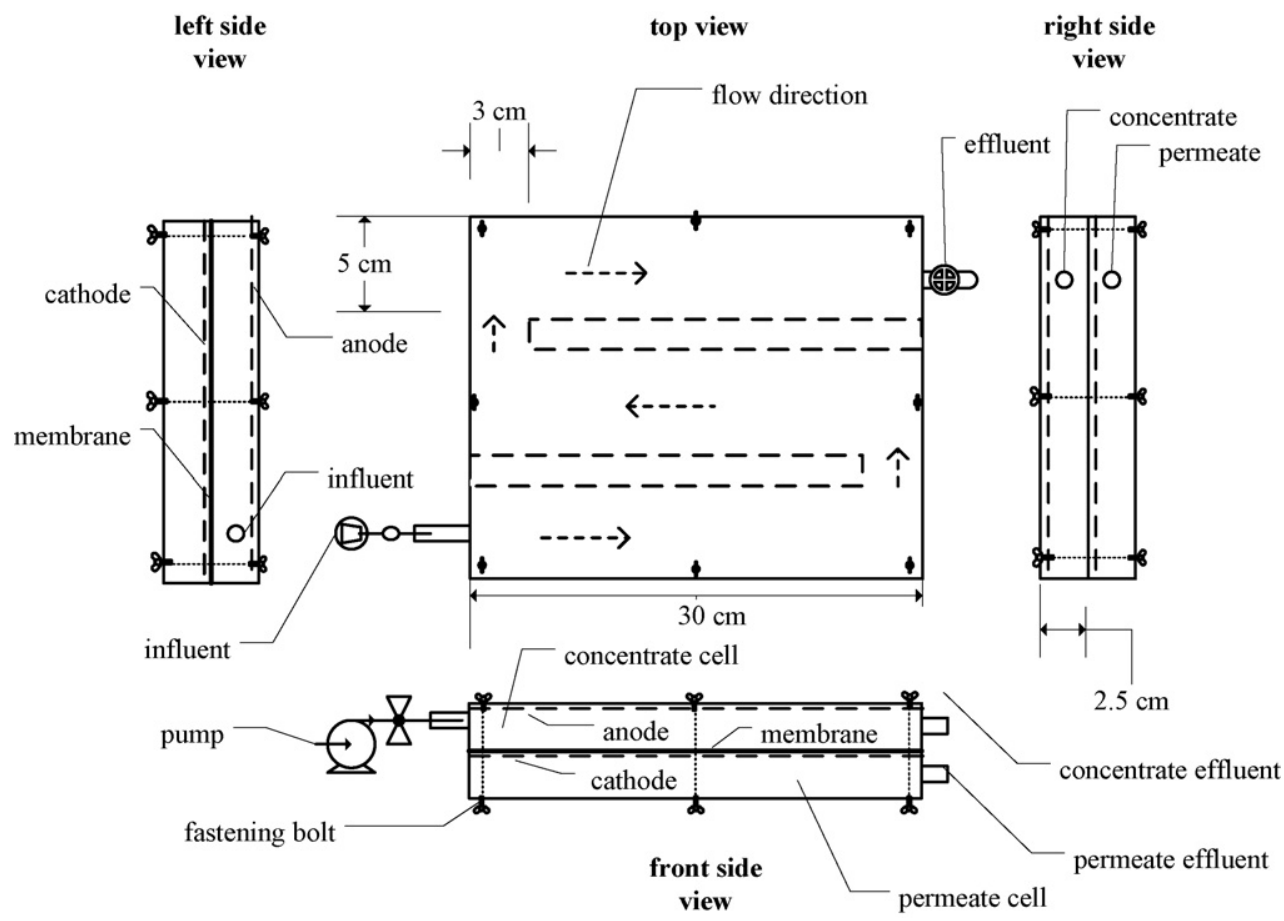

Fig. 1. Cross-sectional presentation of the electrofiltration reactor. 
Particles used include alumina $\left(\gamma-\mathrm{Al}_{2} \mathrm{O}_{3}\right)$ from the Degussa Company (Darmstadt, Germany) and silica $\left(\mathrm{SiO}_{2}\right)$ from Nissan Chemical (Houston, USA). According to the information provided by the manufacturers, the average particle sizes (geometric mean) of $\gamma-\mathrm{Al}_{2} \mathrm{O}_{3}$ and $\mathrm{SiO}_{2}$ are 200 and $84 \mathrm{~nm}$, respectively. Aqueous suspension was prepared as follows. The alumina powder was first dissolved in distilled water and then diluted to about $0.01 \%(\mathrm{w} / \mathrm{v})$ with a turbidity reading between 30 and 40 NTU. Silica was initially in a solution of $40-41 \%(\mathrm{w} / \mathrm{v})$ amorphous silica; it was diluted to about $0.015 \%$ (w/v) with turbidity readings between 45 and 50 NTU.

At the onset of the experiment, the cells were first filled with the prepared colloidal solution, and then the suspension was continuously pumped into the cell from a feed tank at a flow rate of $90 \mathrm{~mL} / \mathrm{min}$, corresponding to a hydraulic retention time of $10.3 \mathrm{~min}$. After $10 \mathrm{~min}$, turbidity in the effluent was measured to ensure that a steady state condition was attained. Once the steady state was achieved, a pre-selected voltage was applied to start the run. Effluent turbidity and conductivity were monitored at fixed time intervals. After each run, the membrane was backwashed with distilled water before starting the next test. To run experiments with the same particles but different $\mathrm{pH}$, suspensions were prepared as previously described except that concentrated strong acid $\mathrm{HCl}$ and strong base $\mathrm{NaOH}$ were added to adjust the feed $\mathrm{pH}$ to specific values.

Analytical instruments used in this study included turbidimeter, Hach ${ }^{\mathrm{TM}}$ Model 2100P (Hach Company, Colorado, USA), conductivity meter (cell constant $=1.0$ ), YSI $^{\mathrm{TM}}$ Model 35 (YSI Incorporated, Ohio, USA) and zetameter, Malvern Zetasizer Model 3000 HAS (Malvern, Worcestershire, United Kingdom). The zetameter was used for electrophoretic mobility and particle size measurements.

\section{Critical field strength and current}

The critical field $\left(E_{\mathrm{c}}\right)$ for a specific particle can be represented by the following equation:

$E_{\mathrm{c}}=\frac{J}{\mu_{\mathrm{EM}}}$

where $J$ is the permeate flux of the solvent and $\mu_{\mathrm{EM}}$ is the electrophoretic mobility of the particle. This equation has been used to calculate the critical field strength of water containing silica, oil particles and humic substances [17-19]. By replacing mobility $\left(\mu_{\mathrm{EM}}\right)$ with zeta potential $(\zeta)$ in Eq. (1) and substituting $J$ with the steady state permeate flow velocity $v_{\mathrm{w}}$, the following equation can be obtained:

$E_{\mathrm{c}}=\frac{6 \pi \eta v_{\mathrm{w}} / f(\alpha)}{\varepsilon \zeta}$

where $\varepsilon$ is the dielectric constant, $\zeta$ the zeta potential, $\alpha=\kappa R, \kappa=2.32 \times 10^{9} \sqrt{2 I}$ (i.e., the reciprocal thickness of the electrical double layer), $I$ the ionic strength and $R$ is the particle radius. For $\alpha<1, f(\alpha)=1$, and for $\alpha>1$, $f(\alpha)=\left((3 / 2)-(9 / 2) \alpha^{-1}+(75 / 2) \alpha^{-2}-330 \alpha^{-3}\right)$. Note that the above $f(\alpha)$ expression is obtained under two assumptions: (i) the ion atmosphere is undistorted by the external field and (ii) the surface potential is low (e.g., $<25 \mathrm{mV}$ ) that allows the use of Debye-Hückel approximation. The $f(\alpha)$ function that relates the zeta potential to $\kappa R$ is in fact the Henry's equation. When $\kappa R \rightarrow 0$, Eq. (2) reduces to the Hückel limit (i.e., $\left.E_{\mathrm{c}}=6 \pi \eta v_{\mathrm{w}} / \varepsilon \zeta\right)$ whereas when $\kappa R \rightarrow \infty$, it reduces to the Helmholtz-Smoluchowski limit (i.e., $E_{\mathrm{c}}=4 \pi \eta v_{\mathrm{w}} / \varepsilon \zeta$ ). Many colloidal particles of interest are present in systems of intermediate $\kappa R$-values; therefore, Henry's equation plays an important role in determining critical voltages under these situations.

It should be emphasized that the $E_{\mathrm{c}}$ term in Eq. (2) was derived from the forces that are directly acting on the particle. Thus, this $E_{\mathrm{c}}$ is different from the voltage actually applied to a system because the drop in voltage at the electrode/solution interface is unknown $[20,21]$. Therefore, one has to calculate the real electric field (i.e., $E_{\mathrm{c}}$ ) from the unambiguous values of the current $(i)$, the cell dimension, and the conductivity $(\lambda)$ of the solution [18]. Alternatively, the current itself can be treated as a parameter that does not need further normalization. One can obtain the critical current $\left(i_{\mathrm{c}}\right)$ from the critical voltage through the relationship, $E_{\mathrm{c}}=i_{\mathrm{c}} / A \lambda$, where $A$ is the surface area of the electrode and $\lambda$ is the conductivity. By substituting this relationship to Eq. (2), the critical current can be written as

$i_{\mathrm{c}}=A \lambda\left[\frac{6 \pi \eta v_{\mathrm{p}} / f(\alpha)}{\varepsilon \zeta}\right]$

\section{Results and discussion}

\subsection{Characterization of particles}

Fig. 2 shows the $\mathrm{pH}$-dependent electrophoretic mobility (EM) of alumina $\left(\gamma-\mathrm{Al}_{2} \mathrm{O}_{3}\right)$ and silica $\left(\mathrm{SiO}_{2}\right)$ used in this study. Fig. 3 shows the results of size measurements as a function of $\mathrm{pH}$. The EM values of alumina were positive between $\mathrm{pH} 2.0$ and 6.0. A drop of EM from positive to negative values between $\mathrm{pH}$ 7.0 and 9.0 was observed. From Fig. 2, the $\mathrm{pH}_{\mathrm{zpc}}$ of $\gamma-\mathrm{Al}_{2} \mathrm{O}_{3}$

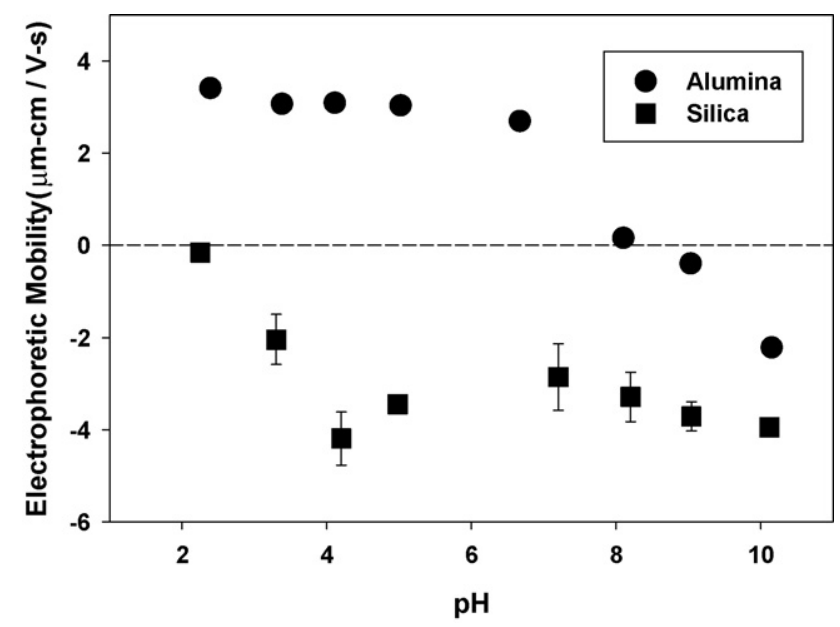

Fig. 2. Electrophoretic mobility of alumina $\left(\mathrm{Al}_{2} \mathrm{O}_{3}\right)$ and silica $\left(\mathrm{SiO}_{2}\right)$ particles as a function of $\mathrm{pH}$. Experimental conditions: (i) $\mathrm{Al}_{2} \mathrm{O}_{3}=1 \times 10^{-4} \mathrm{~g} / \mathrm{L}$ and $\mathrm{SiO}_{2}=1.5 \times 10^{-4} \mathrm{~g} / \mathrm{L}$, (ii) $\mathrm{NaOH}(0.1 \mathrm{M})$ or $\mathrm{HCl}(0.1 \mathrm{M})$ was added for $\mathrm{pH}$ adjustment, (iii) ionic strength values at each $\mathrm{pH}$ are listed in Table 1. 


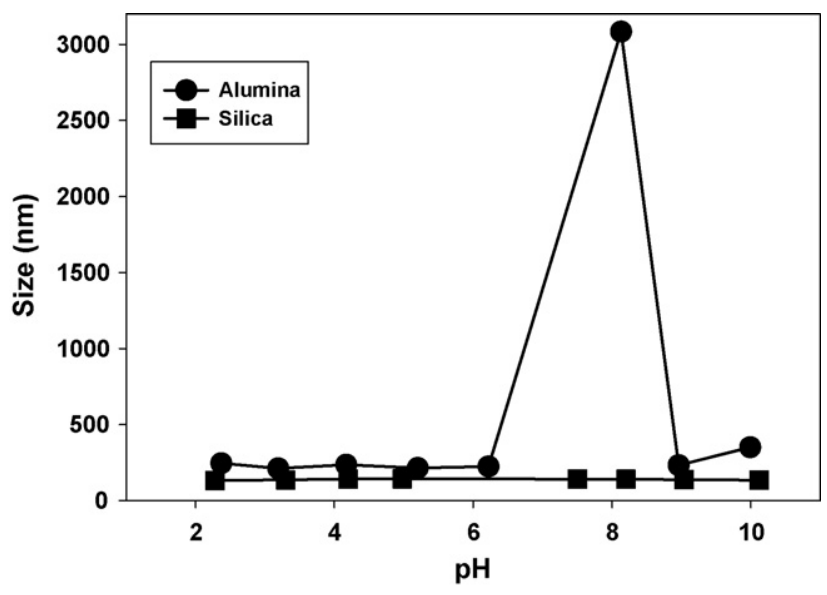

Fig. 3. Particle size distribution as a function of $\mathrm{pH}$. The experimental conditions were the same as those of Fig. 2.

was found to be 8.0 , which agreed well with those reported in the literature $[6,22]$. Results of the particle size analysis under various $\mathrm{pH}$ values (Fig. 3) show that the average particle size of alumina reached a maximum value (increase by a factor of 15 -fold increase, e.g., from ca. $200 \mathrm{~nm}$ to $3 \mu \mathrm{m}$ ) at $\mathrm{pH}$ 8.0. This was expected as coagulation always occurs at $\mathrm{pH}$ values near the $\mathrm{pH}_{\mathrm{zpc}}$. This is evident by a unity polydisperse index at $\mathrm{pH} 8.0$ during size measurements. When the polydisperse index reaches one, the particle size distribution is multidispersed, which is indicative of particle coagulation. As the $\mathrm{pH}$ increases further from 8.0, the $\gamma-\mathrm{Al}_{2} \mathrm{O}_{3}$ particles become much negatively charged which will render the particles re-dispersed (e.g., re-stabilized). As a result, the particle size decreases rapidly. As for the silica particle, its $\mathrm{pH}_{\mathrm{zpc}}$ is 2.0 [6], and thus the particle was negatively charged in the entire $\mathrm{pH}$ range tested (Fig. 2). Therefore, coagulation did not occur with silica, and the size measurements remained rather unchanged at ca. $84 \mathrm{~nm}$.

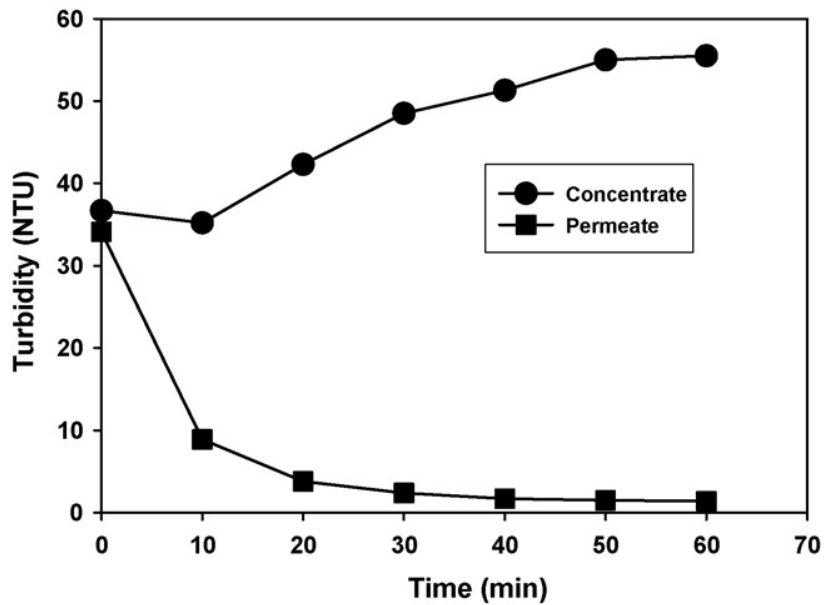

Fig. 4. Transient turbidity measurements of the concentrate and permeate streams. Experimental conditions: (i) $\mathrm{Al}_{2} \mathrm{O}_{3}=1 \times 10^{-4} \mathrm{~g} / \mathrm{L}$, (ii) ionic strength $=5 \times 10^{-6} \mathrm{M}$ as $1: 1$ electrolyte, (iii) $\mathrm{pH} 4.1$.

\subsection{Effects of applied currents and $p H$}

Fig. 4 shows the transient turbidity in concentrate and permeate streams at an applied current of $20 \mathrm{~mA}$ during the electrofiltration of alumina particles. Within the initial $10 \mathrm{~min}$, the turbidity in the permeate stream dropped rapidly from 35 to $<10$ NTU. The turbidity then gradually decreased to near zero at the 60th minute. On the other hand, the turbidity in the concentrate stream increased considerably to $>50$ NTU within 60 min. The opening of the membrane cloth was $3 \mu \mathrm{m}$, which was nearly 15 -fold that of the average primary diameter of the alumina particles (approximately $0.2 \mu \mathrm{m}$ ). In theory this membrane served little purpose in retaining the particles as far as solid-liquid separation is concerned, but in reality it still retained particles to substantial degrees via its tortuous path. However the particle removal process was mainly dependent on the movement of particles to the concentrate stream via electrostatic force. No other effects including cake formation and polarization can influence the hydrodynamic behaviors of particle under the electrostatic field applied. From Fig. 4, it is evident that a steady state concentration in the permeate stream was reached after $40 \mathrm{~min}$. Therefore, in subsequent experiments, only samples at $40 \mathrm{~min}$ were collected and used to calculate the removal efficiency, $\eta$,
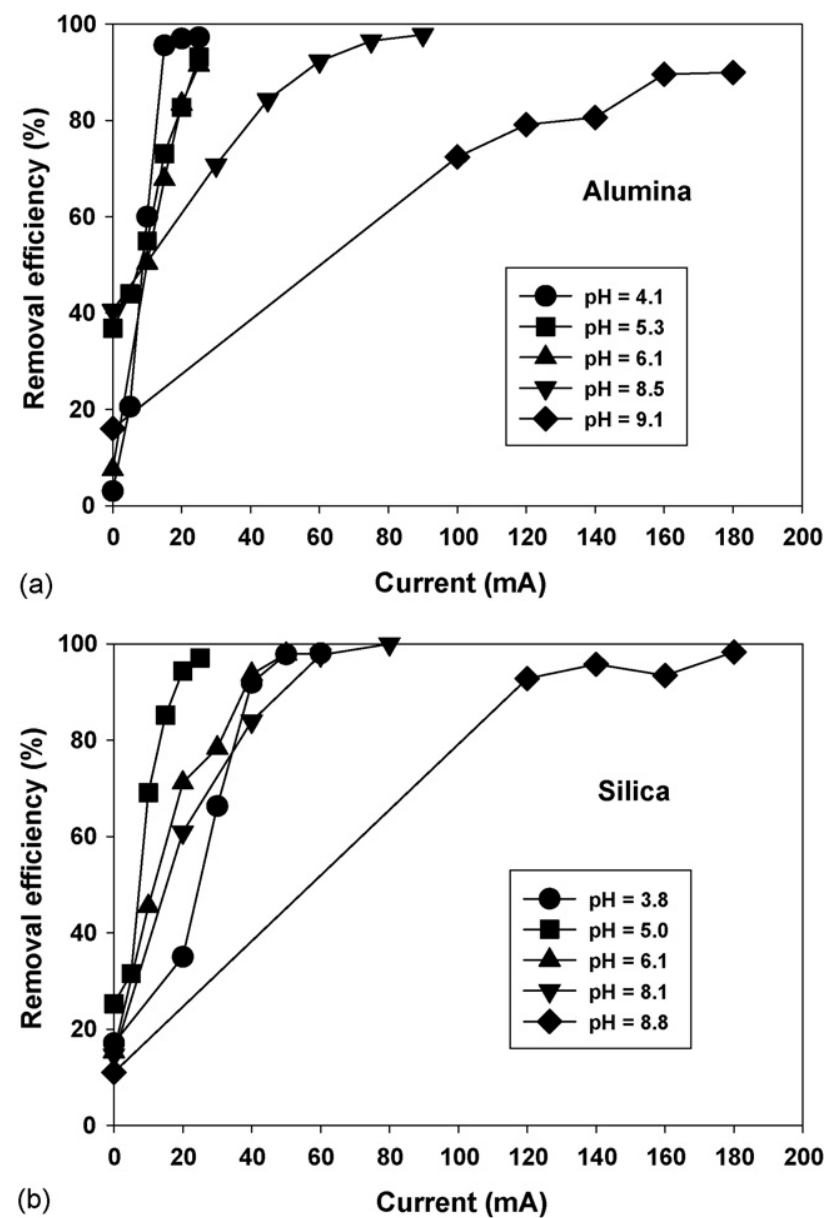

Fig. 5. Particle removal efficiency as a function of current at various $\mathrm{pH}$ values. (a) $\mathrm{Al}_{2} \mathrm{O}_{3}$, (b) $\mathrm{SiO}_{2}$. Experimental conditions: (i) $\mathrm{Al}_{2} \mathrm{O}_{3}=1 \times 10^{-4} \mathrm{~g} / \mathrm{L}$ and $\mathrm{SiO}_{2}=1.5 \times 10^{-4} \mathrm{~g} / \mathrm{L}$, (ii) ionic strength values at each $\mathrm{pH}$ are listed in Table 1 . 
which was determined by the following equation:

$\eta=\frac{C_{0}-C_{f}}{C_{0}} \times 100 \%$

where $C_{0}$ is the influent turbidity and $C_{f}$ is the turbidity of the permeate stream. Fig. 5 shows the removal efficiency of alumina and silica particles at various $\mathrm{pH}$ values and electric currents. Without the presence of a dc voltage (or at zero current), the removal of particles was low, as expected.

It must be mentioned that the polarity of the electrodes were switched accordingly dependent of the $\mathrm{pH}$ value of the suspension as to promote the electrophoretic separation of the filter system. Fig. 5(a) also shows the general trend of the removal efficiency. When the applied current increased, resulted from an increase in the applied electrostatic force exerted on the alumina, the removal efficiency increased, which in turn increased the solid rejection. This increase in particle removal efficiency is valid at all $\mathrm{pH}$ values studied as shown in Fig. 5(a). When the $\mathrm{pH}$ was below $\mathrm{pH}_{\mathrm{zpc}}$ of alumina (i.e., $\mathrm{pH}<8.0$ ), a $>95 \%$ particle removal was achieved at $>20 \mathrm{~mA}$. However, when the $\mathrm{pH}$ values were greater than the $\mathrm{pH}_{\mathrm{zpc}}$ (i.e., $\mathrm{pH}>8.0$ ), higher currents were needed to achieve $>90 \%$ removal. For example, at $\mathrm{pH} 8.5$ it needs a current of $100 \mathrm{~mA}$ to achieve a $100 \%$ particle removal. When the $\mathrm{pH}$ was 9.1, the current of greater than $180 \mathrm{~mA}$ was necessary for a particle removal of $90 \%$. At this particular $\mathrm{pH}$, i.e., 9.1, the removal efficiency did not increase significantly as the current increased from 160 to $180 \mathrm{~mA}$, and a complete removal was not reached at $180 \mathrm{~mA}$, which was close to the maximum power output of our system. To understand how $\mathrm{pH}$ affects the applied currents as described above, it is necessary to know conductivity values at each $\mathrm{pH}$. The initial $\mathrm{pH}$ of the dilute colloidal solution was 4.0, which was correspondent to a conductivity of $3 \mu \mathrm{S} / \mathrm{cm}$. Note that $\mathrm{NaOH}$ was added to raise the $\mathrm{pH}$ value, which

Table 1

Comparison of experimental and calculated critical currents

\begin{tabular}{|c|c|c|c|c|}
\hline $\mathrm{pH}$ & $\lambda(\mu \mathrm{S} / \mathrm{cm})$ & $I(\mathrm{M})^{\mathrm{a}}$ & $\begin{array}{l}\text { Experimental } \\
i_{\mathrm{c}}(\mathrm{mA})\end{array}$ & $\begin{array}{l}\text { Calculated } \\
i_{\mathrm{c}}(\mathrm{mA})\end{array}$ \\
\hline
\end{tabular}

\begin{tabular}{crrrl}
\hline Alumina & & & & \\
4.1 & 3.0 & $5.0 \times 10^{-6}$ & 15 & 16 \\
5.3 & 3.5 & $6.0 \times 10^{-6}$ & 25 & 19 \\
6.1 & 4.3 & $9.0 \times 10^{-6}$ & 25 & 23 \\
8.5 & 9.7 & $2.0 \times 10^{-5}$ & 90 & $\mathrm{n} / \mathrm{a}^{\mathrm{b}}$ \\
9.1 & 26.8 & $5.5 \times 10^{-5}$ & $>180^{\mathrm{c}}$ & 217 \\
Silica & & & & \\
3.8 & 8.6 & $1.0 \times 10^{-5}$ & 40 & 46 \\
5.0 & 3.1 & $4.0 \times 10^{-6}$ & 20 & 17 \\
6.1 & 5.3 & $2.1 \times 10^{-5}$ & 40 & 29 \\
8.1 & 10.7 & $4.3 \times 10^{-5}$ & 60 & 58 \\
8.8 & 30.8 & $12.3 \times 10^{-5}$ & 120 & 166 \\
\hline
\end{tabular}

${ }^{a}$ Ionic strength $(I)$ was calculated using the equation $\Lambda=1000 \lambda / N$, where (i) $\Lambda$ is the equivalent conductance $\left(\mathrm{S} \mathrm{cm}^{3} / \mathrm{eq}\right)$ and was calculated by $\Lambda=\lambda^{+}+\lambda^{-}$ with $\lambda^{+}$and $\lambda^{-}$being the equivalent conductance of the cation and the anion. $\lambda^{+}$for $\mathrm{H}^{+}$and $\mathrm{Na}^{+}$and $\lambda^{-}$for $\mathrm{OH}^{-}$and $\mathrm{Cl}^{-}$are $350,50,199$, and $76 \mathrm{~S} \mathrm{~cm}^{3} / \mathrm{eq}$, respectively [23]. (ii) $N$ is the normality of the solution, which is equal to $I$ in 1:1 salt solution of $\mathrm{NaCl}$.

b Particle aggregation occurred at this $\mathrm{pH}$, therefore the critical current was not available.

c Electrodes were switched at this $\mathrm{pH}$. in turn also brought about an increase in conductivity. Table 1 lists conductivity readings at different $\mathrm{pH}$ values. At $\mathrm{pH}$ 9.1, the measured conductivity was $26.8 \mu \mathrm{S} / \mathrm{cm}$, which was nearly 10 times that at $\mathrm{pH}$ 4.1. This implies that a much higher current is needed to maintain the electric field as suggested from Eq. (3). Note that the critical current is the minimum current for $100 \%$ particle removal. Therefore, one can experimentally determine the value of the critical current by estimating the specific current at $100 \%$ removal. For example, from Fig. 5(a) one can determine that the critical current was around $15 \mathrm{~mA}$ for alumina at $\mathrm{pH} 4.1$ since a near $100 \%$ removal was observed at that current. Analogously, critical currents at other $\mathrm{pH}$ can be obtained by the same manner and their results are summarized in Table 1. Also, it must be mentioned that in the absence of applied electric field, i.e., membrane functions as a filter alone, the percentage of particle removal ranged between 5 and $40 \%$ dependent on $\mathrm{pH}$. As the $\mathrm{pH}$ value is near the $\mathrm{pH}_{\mathrm{zpc}}$, the extent of particle aggregation increased and the particle removal by filtration alone increased. This clearly indicates that the membrane does serve to some extent as a filter in retaining the particles.

Fig. 5(b) shows the removal efficiency of silica at various $\mathrm{pH}$ values and voltages. Since the $\mathrm{pH}$ range studied was greater than the $\mathrm{pH}_{\mathrm{zpc}}$ of the silica, the degree of aggregation was insignificant. At zero currents, only about $15-25 \%$ of particle removal was observed over the $\mathrm{pH}$ range studied, which was in contrast to $5-40 \%$ removal efficiency exhibited by alumina. Note that the initial $\mathrm{pH}$ of the colloidal solution was 5.0. Strong acid or base addition was necessary to adjust the solution $\mathrm{pH}$ to other values other than 5.0. The addition of strong acid or base can modify the conductivity of the solution thereby affect the critical current. From Fig. 5(b), the critical currents were around 25, 50, 60,80 , and $180 \mathrm{~mA}$ at $\mathrm{pH} 5.0,6.1,3.8,8.1$, and 8.8, respectively. As indicated in Fig. 3, the particle size of silica was relatively uniform in the $\mathrm{pH}$ range studied. Therefore it was the intrinsic conductivity that led to the difference in critical current. Only a small critical current was needed to achieve complete removal of silica particles at low conductivity. It is noted that the critical current at $\mathrm{pH} 6.1$ was close to that at $\mathrm{pH} 3.8$ (note that the conductivity of the solutions at $\mathrm{pH} 6.0$ and 3.8 was close to each other, $(5.3 \mu \mathrm{S} / \mathrm{cm}$ versus $8.6 \mu \mathrm{S} / \mathrm{cm}))$. Since much more $\mathrm{NaOH}$ was added at pH 8.1 and 8.8 , than as 5.0 and 6.1 , the critical current increased accordingly.

\subsection{Critical current}

Based on conductivity, particle size, and electrophoretic mobility measurements, it is possible to calculate the critical currents necessary for total particle separation under various size ranges and surface charges (e.g., pH). Table 1 shows the calculated critical currents for our filtration system. Fig. 6 compares experimental and calculated critical currents of alumina and silica under various $\mathrm{pH}$ values. Results clearly show good agreements between the theoretical and the experimental data. As suggested above, the critical current increases as the conductivity increases. For alumina particles, the minimum critical current occurred at ca. $\mathrm{pH} 4$.1, where the conductivity was also at the lowest level. A near-linear increase of critical current was 


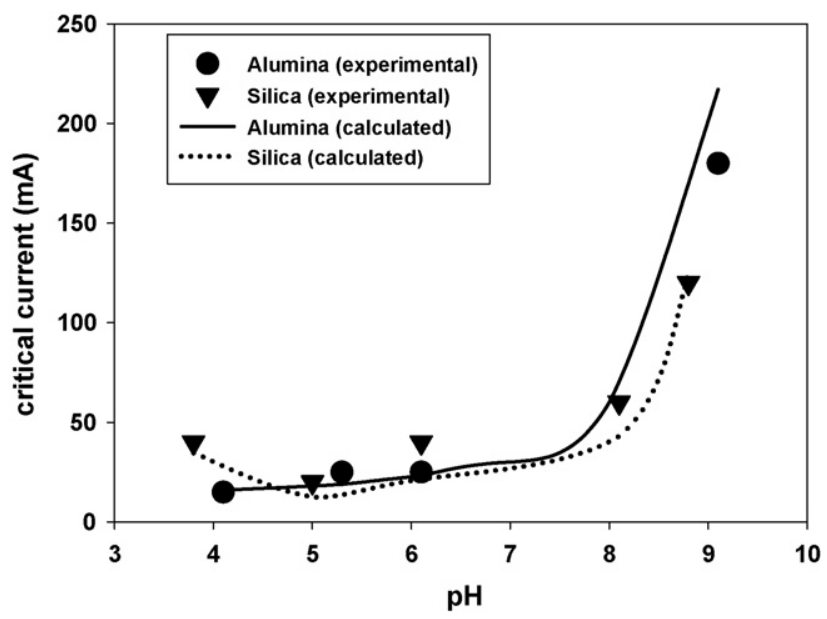

Fig. 6. Critical current as a function of $\mathrm{pH}$ exemplified by alumina $(200 \mathrm{~nm})$ and silica $(80 \mathrm{~nm})$ particles. Experimental conditions: (i) $\mathrm{J}=90 \mathrm{~mL} / \mathrm{min}$, (ii) $\mathrm{Al}_{2} \mathrm{O}_{3}=1 \times 10^{-4} \mathrm{~g} / \mathrm{L}$ and $\mathrm{SiO}_{2}=1.5 \times 10^{-4} \mathrm{~g} / \mathrm{L}$, (iii) ionic strength values at each $\mathrm{pH}$ are listed in Table 1.

observed as the $\mathrm{pH}$ increased from 4.1 to 9.1. For silica particles, the minimum critical current was at ca. $\mathrm{pH}$ 5.0, which was also the initial $\mathrm{pH}$ of the suspension. Note that the conductivity was at its lowest at the initial $\mathrm{pH}$. Upon the addition of $\mathrm{NaOH}$ or $\mathrm{HCl}$, the conductivity increased accordingly. Consequently the critical current increased.

Fig. 7 shows plots of critical current as a function of conductivity for both the alumina and silica. Regardless of particle type (alumina or silica), good correlation was observed between the critical current and the solution conductivity. A linear equation describing the relationship was obtained, that is $i_{\mathrm{c}}=5.18 \lambda$, as shown in the solid line in Fig. 7. Note that according to Eq. (3), the critical current should be zero when the conductivity is zero. Therefore, the regression line must pass through the origin in Fig. 7. At high conductivity values, e.g., $>25 \mu \mathrm{S} / \mathrm{cm}$, the system was operated close to its maximum power capacity. Side reactions such as electrode corrosion could have occurred which may affect the determination of critical current, which has a priori requirement of $100 \%$ particle removal.

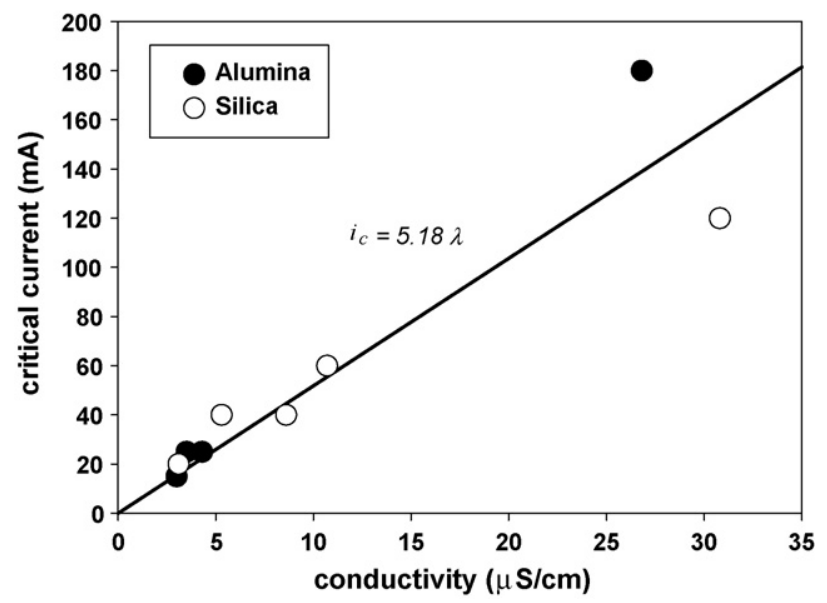

Fig. 7. Experimental critical currents as a function of conductivity for alumina and silica particles.
Eq. (3) describes the dependence of critical current on pertinent factors such as conductivity, particle size, and ionic strength. To this end, the composition of the electrolyte must be specified as to relate ionic strength to conductivity. $\mathrm{NaCl}$ salt was used as the electrolyte used in this study; $\mathrm{NaCl}$ has an anionic $\left(\mathrm{Cl}^{-}\right)$and cationic $\left(\mathrm{Na}^{+}\right)$equivalent conductance of 76.3 and 50.1, respectively. The theoretical conductivity of the suspension at $\mathrm{pH} 7$ was $\lambda=0.0945 C+0.55 \times 10^{-7}$, where $C$ is the molar concentration of $\mathrm{NaCl}$. The second term on the right side of the expression represents the conductivity contributed by $\mathrm{H}^{+}$ and $\mathrm{OH}^{-}$at $\mathrm{pH} 7$.

\subsection{Engineering implications}

Fig. 8 shows the results of the calculated critical current of alumina and silica as a function of particle size under various ionic strengths and conductivities. A few important observations were obvious. For alumina, it is evident that when the conductivity was below a specific value (e.g., $9.5 \mu \mathrm{S} / \mathrm{cm}$ in this case), the critical current remained constant regardless of the particle size. From Eq. (3), it is seen that the only term that the particle size $(R)$ can contribute to the critical current is through the $f(\alpha)$ function, which reflects distortion of the electric field surrounding a particle. The $\kappa R$ value was less than unity when the ionic strength was in the range of $<10^{-4} \mathrm{M}$. This yielded a $f(\alpha)$ value of one. Therefore, the critical current is independent of particle size as long as the $\kappa R$ is less than one. When the ionic strength was increased (e.g., between $1 \times 10^{-4}$ and $1.5 \times 10^{-4} \mathrm{M}$ ), particlesize-dependence of critical current became important. For example, at an ionic strength of $2 \times 10^{-4} \mathrm{M}$ for alumina, the critical

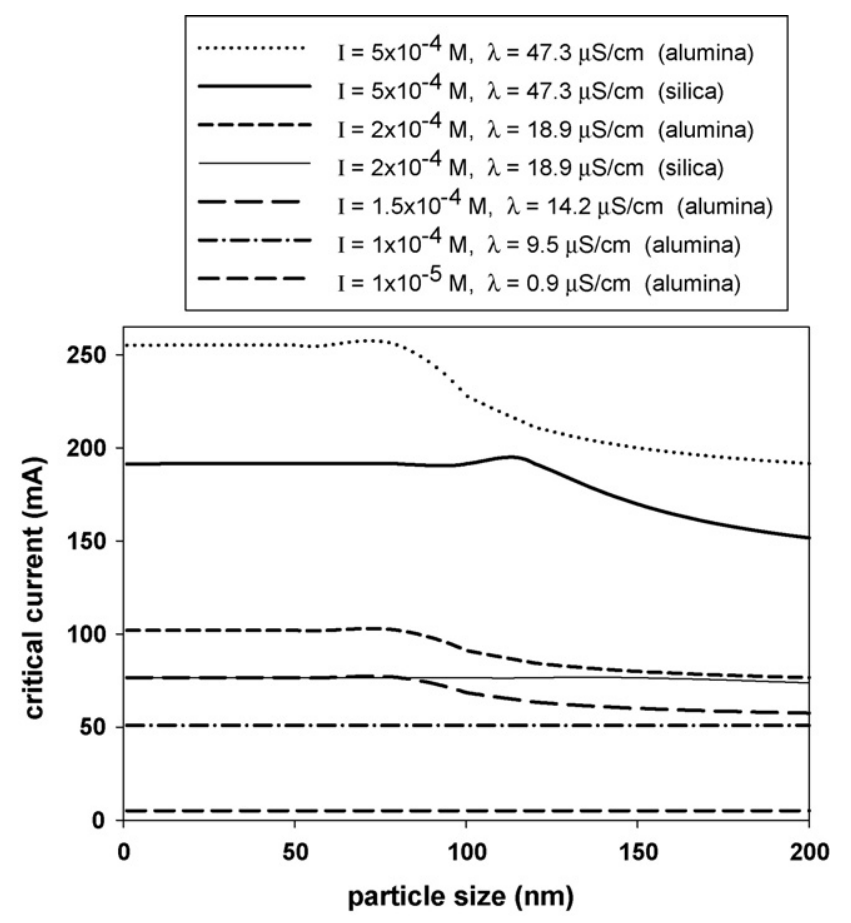

Fig. 8. Calculated critical currents of alumina and silica as a function of particle size under various ionic strengths and conductivities. Note: (i) results for silica and alumina are plotted in solid and dashed lines, respectively, (ii) calculation was carried at $\mathrm{pH} 7$ by considering $\mathrm{NaCl}$ as the electrolyte. 
current was $100 \mathrm{~mA}$ at the particle size of $<80 \mathrm{~nm}$. However, when the particle size increased to $>120 \mathrm{~nm}$, the critical current dropped to $85 \mathrm{~mA}$. Such decrease in critical currents resulted from a $\kappa R$ value being greater than one and $f(\alpha)$ becoming $\kappa R$ dependent. Higher $\kappa R$ values lead to higher $f(\alpha)$, which produces smaller critical currents. Under such circumstance, the critical current decreases and becomes independent of either the ionic strength or the conductivity. For example, critical currents of alumina began to drop at the particle size of ca. $80 \mathrm{~nm}$ under all three different ionic strength, namely $5 \times 10^{-4}, 2 \times 10^{-4}$ and $1.5 \times 10^{-4} \mathrm{M}$ (or conductivity of $47.3,18.9$, and $14.2 \mu \mathrm{S} / \mathrm{cm}$ ) as can be seen from Fig. 8. The drop of critical current with respect to increase in particle size was much remarkable as the conductivity (or ionic strength) increased. Also, it is seen that the silica exhibited smaller critical current drop than alumina under otherwise similar conductivity. This is due to the larger zeta potential of alumina than silica as can be inferred from Eq. (3).

From Fig. 8, one can actually separate nano- to sub-micron particles by applying a specific current across the filter membrane. For example, at an ionic strength of $2 \times 10^{-4} \mathrm{M}$, the critical current of alumina particles was 85 and $100 \mathrm{~mA}$, respectively, for particle size of 120 and $80 \mathrm{~nm}$. By applying a current of $85 \mathrm{~mA}$, it is possible to separate these two groups of particles into two different streams. Since the critical current of the $80-\mathrm{nm}$ alumina particle was $100 \mathrm{~mA}$, only the $120-\mathrm{nm}$ alumina can be collected in the concentrate, leaving the 80-nm alumina particles in the permeate. However, it should be noted that the ionic strength must exceed a certain value for successful separation as is predicted by the $\kappa R$ value.

Also, it is possible to separate particles of the same size but different absolute surface charge, e.g., alumina and silica particles. Generally, the separation is more favorable at higher ionic strength than at lower ionic strength (or conductivity). From Fig. 2, it can be seen that silica has a larger absolute surface charge than alumina over the $\mathrm{pH}$ range studied, i.e., 3.0-10.0. In a solution containing both alumina and silica particles at the same particle size it is possible to separate these two different particles into two different streams at a specific current and ionic strength. For example, at an ionic strength of $5 \times 10^{-4} \mathrm{M}$, the critical current of the alumina and the silica particles at a size of $80 \mathrm{~nm}$ was approximately 260 and $190 \mathrm{~mA}$, respectively. By applying a current slightly larger than $190 \mathrm{~mA}$ or slightly smaller than $260 \mathrm{~mA}$, e.g., $200 \mathrm{~mA}$, the silica particles can be collected in the concentrate whereas the alumina particles will be transported to the permeate, with a successful separation of these two groups of particles. However, when the ionic strength is small, the separation may become limited. As seen from Fig. 8, at an ionic strength of $2 \times 10^{-4} \mathrm{M}$, both the silica and the alumina had similar critical current when the size was greater than $150 \mathrm{~nm}$. Therefore, one cannot separate the alumina and the silica that has particle size larger than $150 \mathrm{~nm}$. On the other hand, the separation of these two particles is achievable when the size is smaller than $150 \mathrm{~nm}$.

The above conductivity limitation can be resolved by redesign of the electrode assembly. Increasing the impedance of the electrode by coating the electrode surface with layers of dielectric materials, e.g., ceramic, can easily solve the problem of having to operate the device under low ionic strength. Once the conductivity is known, the critical currents of interest can be calculated as above.

\section{Conclusions}

It is evident that low-pressure electrofiltration with large poresize membrane offers a viable alternative for the separation of nano-particles. Synthetic nano-alumina and nano-silica particles can be separated readily from solution at specific critical currents. When the $\mathrm{pH}$ is close to the $\mathrm{pH}_{\mathrm{ZPC}}$ of the particle in question, particle aggregation occurs, which will cause significant membrane clogging. The observed critical currents agreed well with theoretical predictions. Although $\mathrm{pH}$ plays an important role in electrofiltration, the conductivity primarily controls the critical current. The conductivity and the critical current are linearly correlated. For the device studied, an empirical critical current to conductivity ratio of 5.18 (mA to $\mu \mathrm{S} / \mathrm{cm}$ ) was obtained. Computation of the critical current as a function of particle size reveals that the separation of particles is feasible. Particles having similar surface charge can be separated only within a limited size range. Generally, adjusting the ionic strength/conductivity can separate particles of similar surface charge in a limited particle size range. Particles of different surface charge can be separated completely without conductivity adjustment. Addition of salt to increase the conductivity can enhance the separation efficiency via increasing the critical current difference.

\section{Acknowledgement}

This research was supported by an exploratory research grant, No. NER 0209246, from the National Science Foundation.

\section{References}

[1] W.I. Oden, G.L. Amy, M. Conklin, Subsurface interactions of humic substances with $\mathrm{Cu}(\mathrm{II})$ in saturated media, Environ. Sci. Technol. 27 (1993) 1045-1051.

[2] A.B. Kersting, D.W. Efurd, D.L. Finnegan, D.J. Rokop, D.K. Smith, J.L. Thompson, Migration of plutonium in ground water at the Nevada Test Site, Nature 397 (1999) 56-59.

[3] B.H. Keswick, C.P. Gerba, Viruses in groundwater, Environ. Sci. Technol. 14 (1980) 1290-1297.

[4] J. Buffle, D. Perret, M. Newman, The use of filtration and ultra filtration for size fractionation of aquatic particles, colloids, and macromolecules, in: J. Buffle, H.P. van Leeuwen (Eds.), Environmental Particles, vol. 1, Lewis Publishers Inc., Chelsea, 1992, pp. 171-230.

[5] G.G. Leppard, Evaluation of electron microscopic techniques for the description of aquatic colloids, in: J. Buffle, H.P. van Leeuwen (Eds.), Environmental Particles, vol. 1, Lewis Publishers Inc., Chelsea, 1992, pp. 231-290.

[6] G. Sposito, Characterization of particle surface charge, in: J. Buffle, H.P. van Leeuwen (Eds.), Environmental Particles, vol. 1, Lewis Publishers Inc., Chelsea, 1992, pp. 291-314.

[7] A.C. Sigleo, G.R. Helz, Composition of estuarine colloidal material: major and trace elements, Geochim. Cosmo. Acta 45 (1981) 2501-2509.

[8] C.T. Chiou, D.E. Kile, T.I. Brinton, R.L. Malcom, J.A. Leenheer, A comparison of water solubility enhancements of organic solutes by aquatic humic 
materials and commercial humic acids, Environ. Sci. Technol. 21 (1987) 1231-1234.

[9] S.A. Sanudo-Wilhelmy, F.K. Rossi, H. Bokuniewicz, R.J. Paulsen, Trace metal levels in uncontaminated groundwater of a coastal watershed: importance of colloidal forms, Environ. Sci. Technol. 36 (2002) 1435-1441.

[10] R. Artinger, W. Schuessler, T. Schaeder, J.I. Kim, A kinetic study of Am(III)/humic colloid interaction, Environ. Sci. Technol. 36 (2002) 4358-4363.

[11] P. Burba, J. Van den Bergh, On-site classification of humic-rich hydrocolloids and their metal species by means of online multistage ultrafiltration, Environ. Sci. Technol. 36 (2002) 4114-4120.

[12] A.P. Tessier, G.C. Campbell, M. Bisson, Sequential extraction procedure for the separation of particulate trace metals, Anal. Chem. 51 (1979) 844-851.

[13] T. Weigert, J. Altmann, S. Ripperger, Crossflow electrofiltration in pilot scale, J. Membr. Sci. 159 (1999) 253-262.

[14] H.M. Huotari, I.H. Huisman, G. Tragardh, Electrically enhanced crossflow membrane filtration of oily waste water using the membrane as a cathode, J. Membr. Sci. 156 (1999) 49-60.

[15] R.J. Wakeman, M.N. Sabri, Utilizing pulsed electric-fields in cross-flow microfiltration of titania suspensions, Chem. Eng. Res. Des. 73 (1995) 455-463.
[16] W.R. Bowen, H.A.M. Sabuni, Electroosmotic membrane backwashing, Ind. Eng. Chem. Res. 33 (1994) 1245-1249.

[17] Y.H. Weng, L.H. Chaung-Hsieh, H.H. Lee, K.C. Li, C.P. Huang, Removal of arsenic and humic substances (HSs) by electro-ultrafiltration (EUF), J. Hazard. Mater. 122 (2005) 171-176.

[18] H.M. Huotari, G. Tragardh, I.H. Huisman, Crossflow membrane filtration enhanced by an external dc electric field: a review, Chem. Eng. Res. Des. 77 (1999) 461-468.

[19] G.C.C. Yang, T.Y. Yang, S.H. Tsai, Cross-flow electro-microfiltration of oxide-CMP wastewater, Water Res. 37 (2003) 785-792.

[20] W.R. Bowen, A.L. Ahmad, Pulsed electrophoretic filter-cake release in dead-end membrane processes, AIChE J. 43 (1997) 959970.

[21] W.R. Bowen, R.S. Kingdon, H.A.M. Sabuni, Electrically enhanced separation processes - the basis of in-situ intermittent electrolytic membrane cleaning (IIEMC) and in-situ electrolytic membrane restoration (IEMR), J. Membr. Sci. 40 (1989) 219-229.

[22] C.P. Huang, W. Stumm, Specific adsorption of cations on hydrous gamma$\mathrm{Al}_{2} \mathrm{O}_{3}$, J. Col. Inter. Sci. 43 (1973) 409-420.

[23] J.A. Dean, Lange's Handbook of Chemistry, 15th ed., McGraw-Hill, Columbus, OH, 1999. 